\title{
Sample Unit Size Effects of Oncomelania hupensis snail on Its Spatial Statistics in the Marshland schistosomiasis Epidemic Area in China
}

\author{
Liu Qing ${ }^{1}$, Zhao An ${ }^{1,2, *}$, Ma Yukuan ${ }^{1}$, Li Cui ${ }^{1}$, Zhang Wenxin ${ }^{1}$ \\ ${ }^{1}$ School of Geography and Environmental Sciences, Jiangxi Normal University, Nanchang City, China \\ ${ }^{2}$ Key Laboratory of Poyang Lake Wetland and Watershed Research, Ministry of Education, Jiangxi Normal University, Nanchang City, China \\ Email address: \\ liuqing7349@qq.com (Liu Qing), zhaoanjxsd@126.com (Zhao An),858154352@qq.com (Ma Yukuan),784120385@qq.com (Li Cui), \\ 546335618@qq.com (Zhang Wenxin) \\ ${ }^{*}$ Corresponding author
}

\section{To cite this article:}

Liu Qing, Zhao An, Ma Yukuan, Li Cui, Zhang Wenxin. Sample Unit Size Effects of Oncomelania hupensis snail on Its Spatial Statistics in the Marshland schistosomiasis Epidemic Area in China. Science Discovery. Vol. 4, No. 3, 2016, pp. 165-172. doi: 10.11648/j.sd.20160403.12

Received: May 11, 2016; Accepted: June 18, 2016; Published: July 5, 2016

\begin{abstract}
Analysis of multi-scale spatial variance and anisotropy was the crucial that should be taken into consideration in optimization of spatial sampling. The aim of this study was to analyse the effect of sampling unit size on perception of spatial variance of Oncomelania snail, the unique schistosomiasis intermediate host. A "push-broom" method was used to investigate Oncomelania snail density in an experimental field, south-western Poyang lake, China, obtaining 22,500 sample cells distributed continuously whole-covered on a square of $50 \mathrm{~m} * 50 \mathrm{~m}$. Combinations of different number of basic sample cells served as spatial sample unit sizes (sample cells from $1 * 1$ to $17 * 17$ ). Geo-statistics was used to calculate the parameters range, nugget, sill of anisotropy variograms for different sample unit sizes to obtain the characteristics of their spatial variance. The results showed that the spatial variance had obvious sample unit size effects. The range had no relationship with the spatial unit sizes (about $50 \mathrm{~m}$ ), but the nugget and sill were associated with the sampling unit sizes. The nugget and the ratio of nugget by sill were inversely associated with sample unit sizes and the random fraction over total spatial variance decreases when sample unit sizes changed from $1 * 1$ to $9 * 9$. The nugget effect became stronger when sample unit sizes changed from $10 * 10$ to $17 * 17$, tallying with the semi-variogram theory. Otherwise, the sill and the difference between sill and the nugget were the biggest when the spatial unit sizes was $8 * 8$. The study implied that the possible optimal sample unit size for explaining the spatial autocorrelation might be at combinations of $8 * 8$ to $10 * 10$ cells for this study field. In conclusion, when in the survey sampling should clearly choose the appropriate sample unit size.
\end{abstract}

Keywords: Oncomelania snail, Sample Unit Size Effects, Spatial Variance, Geo-statistics

\section{中国鄱阳湖血吸虫病疫区湖沼型钉螺空间统计特征的 样点大小效应}

柳庆 $^{1}$, 赵安 ${ }^{1,2, *}$, 马玉宽 ${ }^{1}$, 李翠 ${ }^{1}$, 张文馨 ${ }^{1}$

${ }^{1}$ 江西师范大学地理与环境学院, 江西南昌, 中国

${ }^{2}$ 江西师范大学鄱阳湖湿地与流域研究教育部重点实验室, 江西南昌, 中国

\section{邮箱}

liuqing7349@qq. com（柳庆）, zhaoanjxsd@126. com（赵安）, 858154352@qq. com（马玉宽）, 784120385@qq. com（李翠）, 546335618@qq. com（张文馨） 


\begin{abstract}
摘要：空间尺度问题几乎贯穿了所有地理学分支，其产生的重要原因之一就是地理因子的空间统计特征。地理因子的 空间抽样优化与其空间统计特征具有密切关系，血吸虫的唯一中间宿主-钉螺也不例外。为探索中国鄱阳湖区湖沼型血 吸虫病疫区钉螺空间统计特征的样点大小尺度效应，采用 “推扫式” 方法获取 $50 \mathrm{~m} \times 50 \mathrm{~m}$ 范围内试验样地全覆盖连续分 布的钉螺数量, 通过不同网格数目的组合改变样点尺寸大小，用地统计学方法研究钉螺的空间统计特征与样点尺寸的 变化规律。结果表明：试验样地中不同样点尺寸钉螺数目的变程基本不变（50米左右），样点尺寸由 $1 \times 1$ 至 $10 \times 10$ 网 格数目变化时，块金值、块金基台比与样点尺寸大小呈反比; 当样点尺寸为 $10 \times 10$ 网格数目时，块金值（0.0075）与 块金基台比 (0.0149) 最小，即钉螺数目的空间结构性最强; 当样点尺寸由 $10 \times 10$ 至 $17 \times 17$ 网格数目变化时，块金值、 块金基台比与样点尺寸大小呈正比，即空间依赖减弱；样点尺寸为 $8 \times 8$ 网格数目时，基台值最大（0.5049）。结论： 样点大小对钉螺的空间统计特征有较大影响, 从空间抽样的角度看, 试验样地钉螺调查的适宜样点尺寸应该在 $8 \times 8$ 至 $10 \times 10$ 网格数目之间。
\end{abstract}

关键词：钉螺数量, 样点尺寸效应, 空间特征, 地统计学分析

\section{1. 引言}

尺度是生态学和地理学各学科研究中不容忽视的问题, 表现为不同尺度上相应的尺度效应, 包括: 取样面积（研 究范围) 、取样间距 (分辨率) 和样点大小 (粒度或支撑) $[1,2]$, 生态学研究还应包括观测尺度、生态现象尺度、空 间统计分析尺度等，当样点尺寸、样点形状、样点间距或 研究范围发生改变时, 统计结果 (包括平均值、方差、空 间自相关的强度与特点) 一般也会发生变化 [3]。地理与生 态研究涉及的数据由于都有特定的空间位置, 其隐含的空 间自相关都会产生重复信息 $[4,5]$, 尤其是在土壤学研究中, 对土壤性质信息在不同空间和时间尺度间的转换是土壤科 学研究中的重要问题 [6]。祝俊祥 $[7]$, 潘瑜春 $[8]$, 霍霄妮 [9], 王圣伟 [10]等人运用地统计学技术探讨土壤中有机质 等的含量在多尺度下的空间结构变化特征, 并以此来确定 合理采样间距与采样尺度。因此, 样点的大小、如何配置、 在哪布置等问题都离不开空间统计分析, 成为相关学科研 究的焦点。与经典统计学相比, 空间统计学可以对研究对 象的空间格局进行空间模拟与检验, 定量测度空间尺度和 小于抽样尺度范围内研究对象的空间抽样随机变异，并提 供一个可信程度和误差的评价 [11], 目前已经在生态 [4]、 农业[12]、林业[13]等方面得到了广泛应用。

在生态学领域, 空间统计学除了可以避免经典统计学 的基本假设 (即样本可重复与相互独立) 冲突之外, 其对 不同尺度生态问题的空间格局研究有利于加深用于解释 生态机理的生态过程的理解 [14]。潘杰等 [15]用地统计学 方法分析了受害程度不同的林种内红脂大小蛽空间分布 特征, 并由其空间依赖范围作为抽样设计中确定样点间距 的依据, 得到精度 $80 \%$ 以上的空间抽样方式, 不过该研究 没有涉及样点尺寸的空间统计特征效应; 周灿芳等 [16] 研究发现样方尺寸对南亚热带雨林种群分布格局的经典 统计学指标测定有很大影响。由此可见, 样点尺寸对物种 空间格局具有较大影响, 对空间抽样优化也具有重要意义。

钉螺是血吸虫的惟一中间宿主 [17], 钉螺的地理分布 在一定程度上可以决定血吸虫病疫情的空间分布。与其他 动物类似, 钉螺的空间抽样调查也是一项艰巨的工作, 研 究钉螺的空间分布格局与空间自相关对优化钉螺空间抽 样方案、尽快获得钉螺统计信息具有重要意义。本文用空
间统计学方法研究钉螺空间统计特征的样点大小尺度效 应, 以期为今后钉螺空间抽样优化设计提供科学依据。

\section{2. 材料与方法}

\section{1. 研究区域}

试验调查区为中国江西省新建县恒湖农场茶叶港草洲 (东经 $116^{\circ} 04^{\prime}-116^{\circ} 10^{\prime}$, 北纬 $28^{\circ} 50^{\prime}-29^{\circ} 03^{\prime}$ ), 位于鄱阳湖赣江北支入湖口附近, 冬陆夏水, 钉螺杽生环 境适宜, 另外人为干预灭螺少, 是历史上典型的密螺带。

试验前多次实地踏勘与预试验, 综合考虑植物物种多 样性、高程变化、以及螺情等因素, 在鄱阳湖恒湖农场茶 叶港草洲选择一块 $50 \mathrm{~m} \times 50 \mathrm{~m}$ 的正方形区域作为试验样地。 钉螺数目采集使用由 9 个大小相同网格组成的 $1 \mathrm{~m} \times 1 \mathrm{~m}$ 的样 方框, 每个网格大小是 $0.33 \mathrm{~m} \times 0.33 \mathrm{~m}=0.11 \mathrm{~m} 2$ （如图 1 ）, 即为样本尺寸为网格数目 $1 \times 1$, 这个尺寸也是当前中国血 防部门查螺使用的 1 平方尺框。在实验样地范围内采用“推 扫式” 逐框逐格连续推扫, 最后获计数每个网格的钉螺数 目, 共调查 2500 个样方框 (每个样方框为 $3 \times 3$ 个网格) 的 钉螺数目, 即 22,500 个网格的钉螺数目。

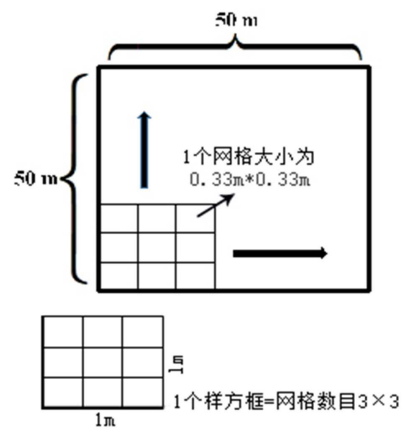

图1 茶叶港钉螺调查分布示意图。

\section{2. 数据处理}

以网格为基本单元, 每个网格几何中心的坐标代表该 样点的空间坐标位置。以左下角网格的几何中心为原点, 采用自定义坐标系统, 由此得到具有空间坐标的钉螺数网 格图。由于现实中的钉螺数目一般偏离正态分布, 于是采 
用王延安 $[18,19]$ 等使用的钉螺数据预处理方法, 将每个 网格的原始钉螺数据进行加 1 取对数, 以满足空间统计分 析的平稳假设条件。

为探索钉螺空间统计特征的样点大小尺度效应, 将试 验样地连续推扫采集的 22,500 个 $1 \times 1$ 网格钉螺数据分别 按 $1 \times 1 、 2 \times 2 、 \cdots 、 17 \times 17$ 数目的网格进行组合作为假设 的样点尺寸, 并假想所有空间抽样方案的样点在空间上连 续排列 (不留空隙)。当样点尺寸为网格数目 $17 \times 17$ 时, 符合试验样地间距的点对数目不足 10 对, 为保证变异函数 结果可信, 故不再将样点尺寸增大。

变异函数的拟合数值的设置往往具有一定的主观性, 为便于比较钉螺数在不同样点尺寸-间距的变异函数效应, 根据计算而得的故在达到足够高的精度下选择拟合统一 的变异函数模型, 便于不同样点尺寸钉螺变异函数参数间 的比较。

\section{3. 研究方法}

\subsection{1. 变异函数}

以 $\mathrm{Z}(x)$ 和 $\mathrm{Z}(x+h)$ 分别表示空间上间隔为 $h$ 的两个样 点的测量值, 则在样本空间内, 所有这些间隔为的样点对间 数值的平均变异程度可用半变异函数 [20]表示, 公式如下:

$$
r(h)=\frac{1}{2 N(h)} \sum_{i=1}^{N}\left[Z\left(x_{i}\right)-Z\left(x_{i}+h\right)\right]^{2}
$$

式中, $r(h)$ 是变异函数, $Z$ 为区域化随机变量, $Z\left(x_{i}\right)$ 和 $Z\left(x_{i}+h\right)$ 分别为变量 $Z$ 在空间位置 $x_{i}$ 和 $x_{i}+h$ 上的取值, $N(h)$ 是空间间隔为 $h$ 的样点对数目。

常用的变异函数模型有球状理论模型、指数模型、高 斯模型、线性模型 $[21,22]$ 。不同的变异函数模型所反应 的研究种群空间结构不一样。球型半变异函数说明所研究 的种群是聚集分布, 其空间结构当样点间距达到变程之前, 其空间依赖性随样点间的距离增大而逐渐变低。指数型和 高斯模型与球型模型类似, 但其基台值呈抛物线型与 $\mathrm{S}$ 曲 线型与先验方差渐近。

反映变异函数曲线结构的参数主要有变程 $\left(A_{0}\right)$ 、基 台值 $\left(C_{0}+C\right)$ 和块金常数 $\left(C_{0}\right)[23]$ 。变程指变异函数 值达到稳定的空间间隔距离, 反映数据样点空间自相关的 平均最大空间距离, 或空间依赖性距离; 基台值指变异函 数达到稳定时的变异函数值, 近似表示数据样点的总变异; 块金值反映了样点观测值的随机性程度，一般来源于两个 方面: (1) 样点本身的随机差异, 可能来自以下三个方面: 一是样点采集的最小抽样间距内确实存在的随机变异; 二 是具有一定大小尺寸 (支撑) 的样点内部的随机变异; 三 是确实存在的相邻样点的数值差异; (2) 数据采集与处理 产生的随机变异, 可能来自以下三个方面: 一是数据采集 过程中产生的可能误差; 二是数据处理时最小间距样点对 数目太少, 计算的变异函数值不稳定; 三是拟合的理论变 异函数与参数设置不恰当。块金值与基台值之比表示样点 观测值的随机性程度引起的空间异质性占总空间异质性的 比例, 比值大于 $75 \%$ 时属于弱空间自相关，比值在 $25 \%$ $75 \%$
时属于中等程度的空间自相关, 比值小于 $25 \%$ 时属于强空间 自相关, 说明区域化变量具有很强的空间结构性 [24]。

变异函数不仅与样点间隔距离有关, 与样点之间的相 对方向也有关系。生物种群格局的各向异性分析有助于更 为细致地分析种群空间分布特征以及种群与环境之间的 关系, 也是进一步开展种群分布格局与其主要受控生态学 过程间关系研究的基础 [25]。生物种群的空间格局经常受 到环境梯度的影响, 特别是受海拔高程的控制, 等高线方 向的变程最长, 空间结构性最为稳定; 而等高线垂直方向 的变程最短, 空间结构性最不稳定 [26]。

\subsection{2. 地统计学各向异性原理}

地统计学各向异性检验是通过方差表面图来进行的, 也就是用一个点图或者一个栅格图层作为数据输入, 计算 半方差值表面, 上面的每一个栅格代表某一“方向-距离” 等级。产出的栅格表面则用一种特殊的地图参考, 帮助我 们从视觉上发现数据中可能存在的各向异性, 并决定各向 异性轴的方向。然后, 我们可以用空间相关分析中的 “双 向” 方法来计算方向性半方差值。在空间相关产出表上, 我们可以初步决定各向异性的主轴方向及其相应的垂直 方向, 然后决定用哪个半方差理论模型来对数据进行拟合, 并估计变量的变异行程。

为了进行方差图表面计算, 所用图层值域应是数值, 或者与一个含有数值列的属性表联接的等级或标识图层。 方差图表面运算的结果是一个标识图, 以栅格图方式表示, 原点位于图的中心。标识图上每一个格子 (即栅格图里的 每一个像元) 的数值用来计算方差图的基本距离间隔大小 （一般取决于样本点的空间排列与间距）, 产出图中从原 点到 $X$ 轴或 $Y$ 轴边缘的格子数目是由我们根据需要指定的 基本距离单元的若干倍数。因此, 图上每一格子代表了“方 向-距离” 等级, 数值则是分隔向量那个格子对应的所有 点对的半方差值。

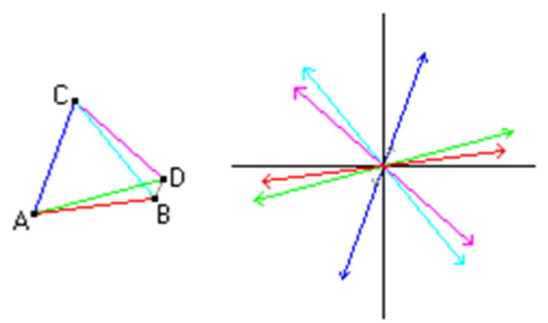

图2 点图矢量示意图。
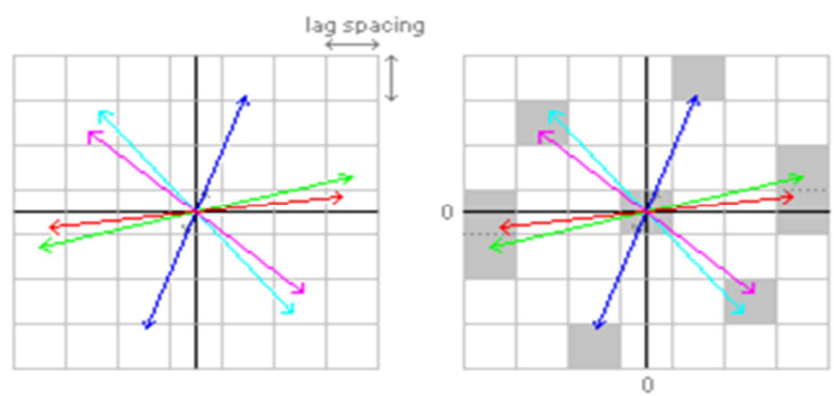

图3 分离矢量示意图。 
图 2 代表了输入图上的四个点，每个点对用一个不同 颜色的线表示一个点对的分隔向量。图3中的格网代表了 方差图的基本间隔距离, 每个栅格点代表了方差图表面上 的一个方向一距离等级。为了取得较好的计算结果, 图上 每个格子 (即棚格图里的每一个像元) 的半方差值应该至 少由 30 个点对计算得到，0代表计算结果图空间参考的原 点位置。

\section{3. 结果与分析}

用荷兰ITC开发的遥感/GIS软件ILWIS3.8进行空间统 计各向异性分析，拟合不同空间抽样方案假想样点尺寸下 钉螺数目的半变异函数模型, 其计算有关空间统计特征参 数结果如下表 1 。

表1 不同样点尺寸钉螺数量的变异函数最优理论模型及相关统计参数。

\begin{tabular}{|c|c|c|c|c|c|c|c|c|c|c|}
\hline 网格组合 & 样点数目 & 实际网格总数 & $\begin{array}{l}\text { 变程 } \\
\mathrm{A} 0(\mathrm{~m})\end{array}$ & $\begin{array}{l}\text { 块金值 } \\
\text { C0 }\end{array}$ & $\begin{array}{l}\text { 基台值 } \\
\mathrm{C} 0+\mathrm{C}\end{array}$ & C & $\frac{C_{0}}{C_{0}+C}$ & $r^{2}$ & $\begin{array}{l}\text { 各向异性 } \\
\text { 方向 }\end{array}$ & $\begin{array}{l}\text { 最优理论 } \\
\text { 模型 }\end{array}$ \\
\hline $1 \times 1$ & 22500 & 22500 & 51.9615 & 0.0502 & 0.4772 & 0.4270 & 0.1052 & 0.9944 & $90^{\circ}$ & G \\
\hline $2 \times 2$ & 5625 & 22500 & 51.9615 & 0.0180 & 0.4522 & 0.4342 & 0.0398 & 0.9894 & $90^{\circ}$ & G \\
\hline $3 \times 3$ & 2500 & 22500 & 53.6936 & 0.0116 & 0.4731 & 0.4615 & 0.0245 & 0.9940 & $90^{\circ}$ & G \\
\hline $4 \times 4$ & 1369 & 22336 & 57.1577 & 0.0092 & 0.5024 & 0.4932 & 0.0183 & 0.9912 & $85^{\circ}$ & G \\
\hline $5 \times 5$ & 900 & 22500 & 55.4256 & 0.0079 & 0.4916 & 0.4837 & 0.0161 & 0.9919 & $85^{\circ}$ & G \\
\hline $6 \times 6$ & 625 & 22500 & 55. 4256 & 0.0077 & 0.4735 & 0.4658 & 0.0163 & 0.9904 & $90^{\circ}$ & G \\
\hline $7 \times 7$ & 441 & 21609 & 57. 1577 & 0.0079 & 0.5017 & 0.4938 & 0.0157 & 0.9887 & $90^{\circ}$ & G \\
\hline $8 \times 8$ & 324 & 20736 & 57. 1577 & 0.0078 & 0.5049 & 0.4971 & 0.0154 & 0.9858 & $85^{\circ}$ & G \\
\hline $9 \times 9$ & 256 & 20736 & 55.4256 & 0.0077 & 0.4646 & 0.4569 & 0.0166 & 0.9815 & $90^{\circ}$ & G \\
\hline $10 \times 10$ & 225 & 22500 & 57.1577 & 0.0075 & 0.5017 & 0.4942 & 0.0149 & 0.9876 & $85^{\circ}$ & G \\
\hline $11 \times 11$ & 196 & 23716 & 57. 1577 & 0.0085 & 0.4790 & 0.4705 & 0.0177 & 0.9776 & $85^{\circ}$ & G \\
\hline $12 \times 12$ & 144 & 20736 & 55.4256 & 0.0097 & 0.4898 & 0.4801 & 0.0198 & 0.9787 & $80^{\circ}$ & G \\
\hline $13 \times 13$ & 121 & 20449 & 53. 6936 & 0.0100 & 0.4395 & 0.4295 & 0.0228 & 0.9688 & $85^{\circ}$ & G \\
\hline $14 \times 14$ & 100 & 19600 & 51.9615 & 0.0111 & 0.4195 & 0.4084 & 0.0265 & 0.9674 & $80^{\circ}$ & G \\
\hline $16 \times 16$ & 81 & 20736 & 51.9615 & 0.0126 & 0.4204 & 0.4078 & 0.0300 & 0.9680 & $85^{\circ}$ & G \\
\hline $17 \times 17$ & 64 & 18496 & 50.2295 & 0.0142 & 0.4427 & 0.4285 & 0.0321 & 0.9517 & $90^{\circ}$ & G \\
\hline
\end{tabular}

G：高斯模型；各向异性方向角：以正北方向为 $0^{\circ}$

\section{1. 不同样点尺寸下钉螺数目变异函数的各向异性与理 论模型}

表1结果显示: 该试验样地的钉螺数目具有明显的空 间依赖性（或空间自相关性），样点尺寸为网格数目 $1 \times 1$ 至 $17 \times 17$ 的变程范围在 $50.2295 \mathrm{~m}^{\sim} 57.1577 \mathrm{~m}$, 即基本上所 有样点均在其变程范围内; 另外它们的半变异函数拟合的
高斯模型球型优度皆在 $95 \%$ 以上, 说明所研究的种群是聚 集分布。如图 4 中样点尺寸为网格数目 $1 \times 1 、 8 \times 8 、 10 \times$ 10、 $17 \times 17$ 时 4 个样点尺寸的变异函数曲线图显示, 其空 间结构当样点间距达到变程之前, 样点间的空间依赖性随 样点对的距离增大而逐渐变低, 相似性逐渐减小, 钉螺数 目的空间差异性逐渐增加, 半变异函数值增大。
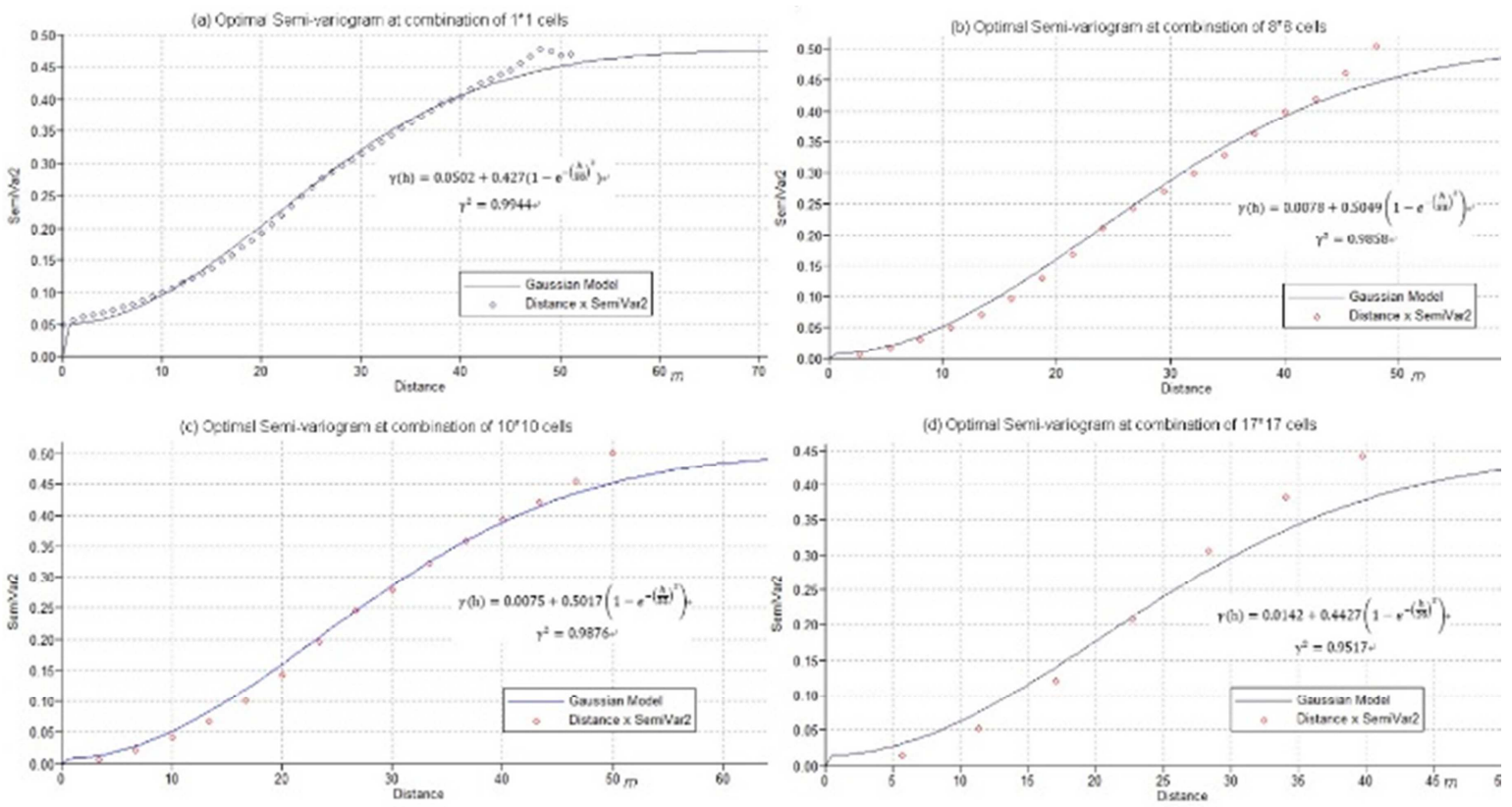

图4 试验样地钉螺样点尺寸为网格数目 $1 \times 1 \times 1 、 8 \times 8 、 10 \times 10 、 17 \times 17$ 的最优高斯变异函数模型拟合。 
ILWIS3.8软件中方差表面分析结果（如图5），图为 该实验样地样点尺寸为格点数目 $1 \times 1$ 至 $17 \times 17$ 时钉螺数 目的方差值, 蓝色为低值, 红色为高值。图中表明不同样 点尺寸的钉螺数据具有明显的各向异性, 方差表面图的长 轴方向与样地水平方向（方位角大致 $80^{\circ} \sim 90^{\circ}$ ）基本平 行, 也与试验样地的等高线趋势基本保持平行, 说明这个 方向的变异函数空间结构性明显而稳定，与赵安等 [26] 的研究结果相同。不同样点尺寸在水平方向建立的最优变 异函数模型皆为高斯模型, 即样点数据的变异函数曲线总 体形状基本相同, 与Fortin[27]对木本植物丰度的多尺度 （样点大小）空间统计类似研究结果基本一致。

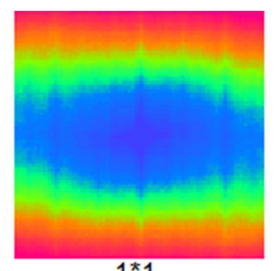

$1 * 1$

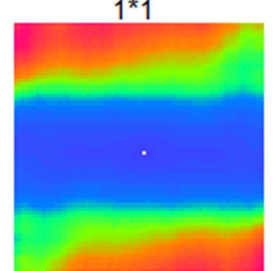

$4 * 4$
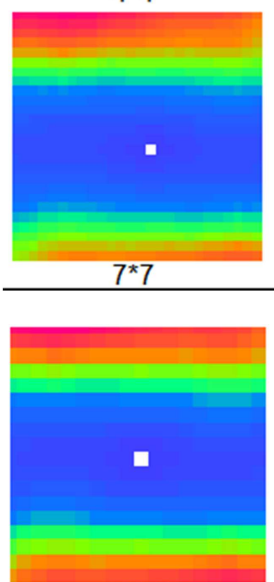

$10 * 10$

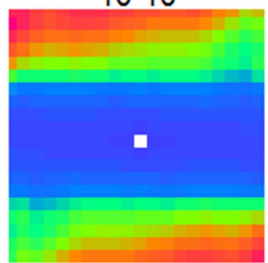

$13 * 13$

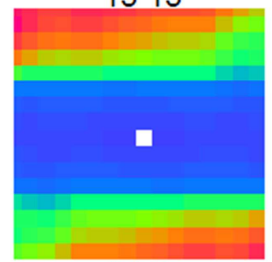

$16^{\star} 16$

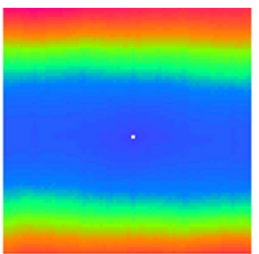

$2 * 2$

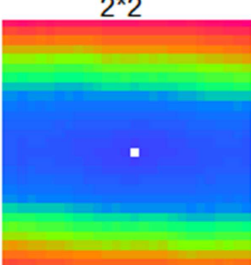

$5 * 5$

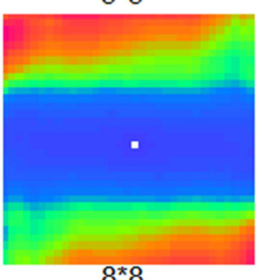

$8^{\star} 8$

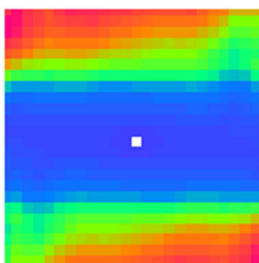

$11^{\star} 11$

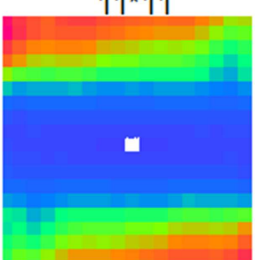

$14^{\star} 14$

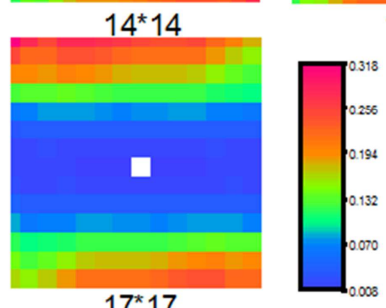

$17^{\star} 17$

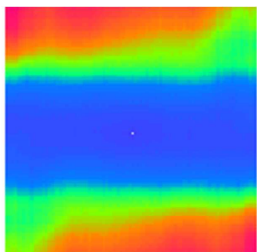

$3^{\star} 3$

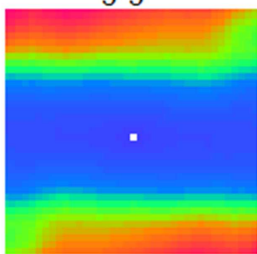

$6^{\star} 6$

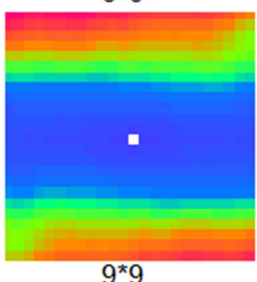

$9 * 9$

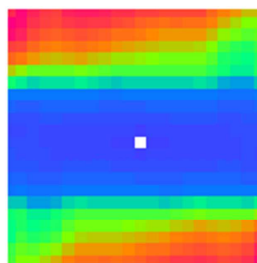

$12^{\star} 12$

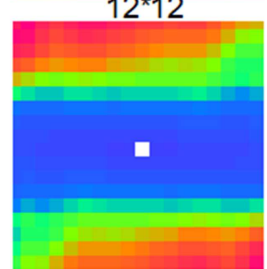

$15 * 15$

$\uparrow$
图5 不同样点尺寸的钉螺数据的方差表面图。

\section{2. 块金方差的样点大小尺寸效应}

由于各种假想的空间抽样方案样点间距是 0 , 而数据 采集的误差相对总块金方差一般所占比例很小 [28]，因此 本研究得到的块金方差主要反映了不同样点尺寸内部的 随机变异，其实也反映了块金方差的样点大小尺度效应。 生物种群一般总是呈聚集分布, 聚集原因可分为本身的生 物学特性和环境因素两个方面, 在小尺度上, 钉螺的空间 聚集主要是由其生物习性决定的, 而随着尺度的增大, 其 空间聚集则是由生物习性与环境因子 (这里主要是食物) 共同作用产生的。在所有各种假想的空间抽样方案中, 最 小样点尺寸 (网格数目 $1 \times 1)$ 的块金值最大 (0.0502), 说明此样点尺寸内部钉螺分布的非空间结构随机变异最 明显, 反映此样点尺寸内部环境因子对钉螺影响产生的空 间变异相对较小 (原因是环境因子的空间变异尺度相对较 大）, 也反映了钉螺自身生物因子相互吸引产生的空间聚 集性较强, 与尤海舟 [29] 等对中国川滇高山栎种群不同海 拔空间格局的尺度效应研究结果基本相同, 也与Hi11 [30] 等对棉地昆虫的空间统计研究结果类似。当样点尺寸由网 格数目 $2 \times 2$ 变化至 $17 \times 17$ 时, 该试验样地钉螺数目的块金 值与样点尺寸大小呈U字形相关 (如图6), 样点尺寸为网 格数目 $2 \times 2$ 时的块金值为 0.0180 , 为网格数目 $10 \times 10$ 时块 金值最小 $(0.0075)$, 为网格数目 $17 \times 17$ 时块金值又上升 至0.0142。根据Cox [31] 的观点 “一定大小的取样测度是 受该大小面积上起作用的环境因子影响的格局” 和 Kershaw [32] 的观点 “当样方大小近似等于生物个体集群 斑块大小时样本数据的方差最大”。因此, 该结果说明: 随着样点尺寸从网格数目 $2 \times 2$ 变化到 $10 \times 10$, 钉螺自身生 物因子相互吸引产生的空间聚集性较越来越弱, 而样点尺 寸内部环境因子对钉螺影响产生的空间变异越来越强, 当 样点尺寸为网格数目 $10 \times 10$ 时样点尺寸内部钉螺分布的 非空间结构随机变异最弱, 样点尺寸内部环境因子对钉螺 影响产生的空间结构性变异最强, 也反映了这个抽样尺寸 环境因子的空间结构性最强; 当样点尺寸为网格数目 17 $\times 17$ 时, 样点尺寸内部钉螺的空间分布主要受环境因子控 制, 由于这个抽样尺寸超过了环境因子的最适抽样尺寸, 圥余信息较多, 导致这个样点尺寸下环境因子对钉螺影响 产生的空间结构性变异相对样点尺寸为网格数目 $10 \times 10$ 时有所下降，随机性增大，于是块金值相应增大。

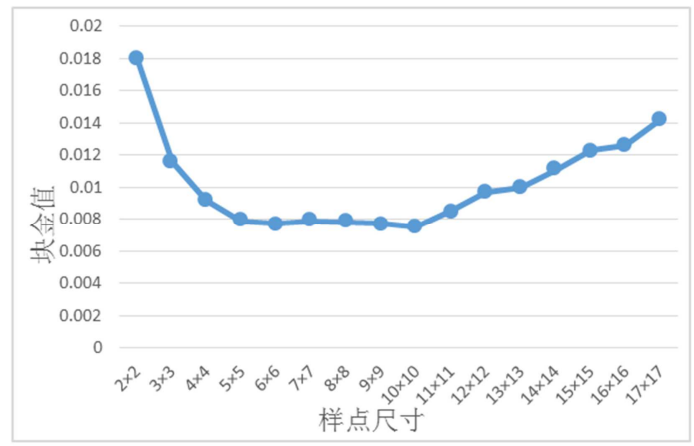

图6 当样点尺寸由网格数目 $2 \times 2$ 变化至 $17 \times 17$ 时, 该试验样地钉螺数目 的块金值与样点尺寸大小呈 $\mathrm{U}$ 字形相关。 


\section{3. 基台值的样点大小尺寸效应}

该实验样地钉螺基台值随样点尺寸为网格数目 $1 \times 1$ 至 $17 \times 17$ 的变化没有明显的逐渐增大或减小趋势，且其基 台值之间的差值不大于 0.1 , 与Tobin[33] 对草地甲虫的空 间统计学研究结果类似。最大基台值出现在样点尺寸为网 格数目 $8 \times 8$ 时，基台值为 0.5049 ，且其基台值与块金值间 的差最大为 0.4971 , 即在样点尺寸为网格数目 $8 \times 8$ 时, 反 映了这个样点尺寸空间抽样方案的钉螺数目差异最大, 代 表样本获得的钉螺数目的空间差异信息最多。Kershaw [34] 指出: 当样方大小近似等于生物个体集群斑块大小时样本 数据的方差最大, 因此这个结果隐含表明: 本试验样地钉 螺聚集团块大小的众数为 $(8 \times 0.33) \times(8 \times 0.33)$, 即 $2.64 \mathrm{~m} \times 2.64 \mathrm{~m}$ 左右。

\section{4. 块金基台比的样点大小尺寸效应}

该试验样地钉螺其块金基台比皆小于 $25 \%$ ，属强空间 自相关, 说明该试验样点内钉螺具有很好的空间结构。样 点尺寸为网格数目 $1 \times 1$ 时, 其块金与基台比值在所有样点 尺寸中最大, 为 0.1052 , 说明该试验样地钉螺在此样点尺 寸的空间异质性有 $10.52 \%$ 是由随机因素贡献的, 并在所探 究样点尺寸中随机部分的影响最大, 而 $89.48 \%$ 的变异则是 空间自相关贡献的。随着样点尺寸为网格数目 $2 \times 2$ 变化到 $17 \times 17$ 时, 由于其基台值之间的差值不大，即分母之间变 化差值小, 其块金基台比的变化趋势与块金值变化趋势相 似。当样点尺寸为网格数目 $10 \times 10$ 时, 其块金与基台比值 在所有抽样尺寸中最小（为0.0149）, 该试验样地钉螺在 此样点尺寸的空间异质性有 $1.49 \%$ 是由随机因素贡献的, 且在所探究样点尺寸内随机部分的影响小, 而98.51\%的变 异是由钉螺自身空间自相关贡献的, 说明在这个尺寸上其 空间分布格局变化最复杂, 其半变异函数检测出更多空间 自相关造成的变异。这个结果与Bellehumeur [35]等对乔 本植物的类似研究和Rossi等 [36]对一个自然保护区的虹 蚓粪的类似研究结果不尽相同, 后面二者随机部分引起的 空间异质性占总空间异质性的比重随样点尺寸的增大而 单调下降。

\section{4. 结论}

与经典统计学相比, 地统计学分析可以获取实验数据 结果变异函数特征参数及其变异函数模型, 所获取的空间 变异特征信息更加丰富、可靠。从空间抽样的角度来看, 调查研究时的样点尺寸大小对探究对象空间结构特征有 很大影响 [37, 38]。我们总是希望样点之间的差异尽可能 大并保持样点观测值相互独立, 而钉螺空间聚集总是由环 境因子与生物因子共同作用产生, 因此, 如何选择最适宜 的样点尺寸需要在样点尺寸内部环境因子对钉螺分布影 响产生的空间变异相对较小与钉螺自身生物因子相互吸 引产生的空间聚集性对钉螺分布影响产生的空间变异相 对较小之间进行平衡, 而不仅仅考虑样点之间的钉螺空间 自相关结构性问题。

目前, 中国血防部门在湖沼型钉螺调查时所采用的样 本框大小为 $0.33 \mathrm{~m} \times 0.33 \mathrm{~m}$, 即本文中样本尺寸为网格数目
$1 \times 1$ 的大小。而此次实际调查中, 在 $50 \mathrm{~m} \times 50 \mathrm{~m}$ 草洲范围内 用网格（大小为 $0.33 \mathrm{~m} \times 0.33 \mathrm{~m}$ ) 全覆盖采集获得该范围内 钉螺数据 “真值” , 获取 17 种样点间距是 0 的不同样点大 小尺寸空间抽样方案, 即固定样点间的间距, 探讨钉螺数 量的空间统计特征的样点大小尺度效应。另外, 该实验样 方大小为网格数目 $2 \times 2$ 至 $17 \times 17$ 在样方大小的合并过程 中, 如样方大小为网格数目 $4 \times 4$ 的空间抽样方案的实际网 格总数小于样方大小为网格数目 $3 \times 3$ 全覆盖调查网格总

数, 但并未影响其结果整体趋势。

该试验样地的钉螺数目具有明显的空间依赖性 (或空 间自相关性）, 样点尺寸为网格数目 $1 \times 1$ 至 $17 \times 17$ 的变程 范围在 $50.2295 \mathrm{~m}^{\sim} 57.1577 \mathrm{~m}$, 即基本上所有样点均在其变 程范围内。试验样地钉螺在不同样点尺寸下皆属于等间距 规则网格数据, 这种数据其数据结构一致, 并通过ILWIS 软件在方差表面分析验证得出不同样点尺寸钉螺变量皆 在同一方向上有明显变化。

在所有各种假想的空间抽样方案中, 最小样点尺寸网 格数目 $1 \times 1$ 的块金值最大, 说明此样点尺寸内部钉螺分布 的非空间结构随机变异最明显, 钉螺自身生物因子相互吸 引产生的空间聚集性较强, 但此样点尺寸内部环境因子对 钉螺影响产生的空间变异相对较小; 当样点尺寸为网格数 目 $10 \times 10$ 时块金值最小，样点尺寸内部钉螺分布的非空间 结构随机变异最弱, 样点尺寸内部环境因子对钉螺影响产 生的空间结构性变异最强; 另外, 样点尺寸为网格数目 8 $\times 8$ 时基台值与块金值间的差最大，本试验样地钉螺聚集 团块大小的众数出现在这个样点尺寸空间抽样方案下, 获 得的钉螺数目的差异最大、空间差异信息最多。

本次试验中, 在鄱阳湖草洲连续推扫调查所获取钉螺 数量, 受时间人力物力的限制, 故仅调查 $50 \mathrm{~m} \times 50 \mathrm{~m}$ 大范围 的草洲, 这个范围对于鄱阳湖整个有螺草洲来说并不能作 为代表典型。但不能否认的是, 该实验样地钉螺的样点大 小尺寸效应较明显, 今后的实验中将模拟实际调查同时探 讨样点间距与样点大小尺寸同时变化时, 将会发生的钉螺 空间统计特征变化效应。

\section{致谢}

本文得到中国国家自然科学基金项目《湖沼型血吸虫 病疫区钉螺分布空间抽样优化研究》(81260449) 与中国江 西省教育厅科技项目《湖沼型血吸虫病疫区钉螺调查方法 的优化研究》（CJJ12185）的支持。

\section{参考文献}

［1］张法升, 刘作新, 张颖等. 农田土壤有机质空间变异的尺度 效应 [J]. 中国科学院研究生院学报, 2009, 26 (3) :350-356。

[2] Carroll S S and Pearson D L. The effects of scale and sample size on the accuracy of spatial predictions of tiger beetle (Cicindelidae) species richness[J]. Ecography 1998, 21: 401-414. 
[3] Dungan J L, Perry J N, Dale M R T, et al. A balanced view of scale in spatial statistical analysis $[\mathrm{J}]$. Ecography, 2002, 25: 626-640.

[4] Vallejos R and 0sorio F. Effective sample size of spatial process models[J]. Spatial statistics, 2014 (9) : $66-92$.

[5] Griff D A. Effective geographic sample size in the presence of spatial autocorrelation[J]. Annals of the Association of American geographers, 2005, 95(4): 740-760.

[6] Wagenet R J. Scale issues in agroecological research chains [J] . Nutrient Cycling in Agroecosystems. 1998, 50: $23-34$.

[7] 祝俊祥, 王卷乐. 基于半方差函数的复杂场景地物适宜尺度 分析 [J]. 地理与地理信息科学, 2015, 31(4)：33-37。

８］潘瑜春, 刘巧芹, 阎波杰, 等. 采样尺度对土壤养分空间变异 分析的影响 $[\mathrm{J}]$. 土壤通报, 2010, 41 (2)：257-262。

[9] 霍霄妮, 李红, 张微微, 等. 北京耕作土壤重金属多尺度空间 结构 [J].农业工程学报. 2009, 25 (3)：223-229。

[10] 王圣伟, 冯娟, 刘刚, 等. 多嵌套空间尺度农田土壤重金属空 间变异研究 [J].农业机械学报, 2013，44(6)：128-135。

[11] 葛剑平, 郭海燕, 仲莉娜, 地统计学在生态学中的应用 (I) 一基本理论和方法 $[\mathrm{J}]$. 东北林业大学学报, 995 (02) : 88-94.

[12] 李琳一, 袁涛, 陈旭. 农业抽样调查中统计理论和抽样方法 选取研究 $[J]$.上海农业学报, 2011, 27 (4)：5-8。

[13] 陈雄文, 张新时, 周广胜等. 中国东北样带 (NECT) 森林区 域中主要树种空间分布特征 [J]. 林业科学, 2000, 36 (6) : 35-38。

[14] Vaclavik T, Kupfer J A and Meentemeyer R K. Accounting for multi-scale spatial autocorrelation improves performance of invasive species distribution modeling (iSDM) [J]. Journal of Biogeography, 2012 (39) : $42-55$

[15] 潘杰, 王涛, 宗世祥等. 红脂大小蛽种群空间格局第统计学 分析及抽样技术 [J]. 生态学报, 2011, 31 (1)：195-202。

[16] 周灿芳, 余世孝, 郑业鲁等. 种群分布格局测定的样方尺度 效应 $[J]$. 广西植物，2003，23(1)：19-22。

[17］中华人民共和国卫生部地方病防治司, 血吸虫病防治手册 [M]. 1990, 上海: 上海科学技术出版社. 29-51。

[18] 王延安, 伍卫平, 华政辉等, 全国血吸虫病抽样调查样本量 估算方法的探讨 $[J]$. 中国寄生虫学与寄生虫病杂志, 1998(03) : 76-77。

[19] 王延安, 伍卫平, 华政辉等血吸虫感染度几何均数的换算 公式 [J]. 中国寄生虫学与寄生虫病杂志, 1998(02):38。

[20] Cressie, N., Statistics for spatial data [M]. 1993, Wiley Interscience
[21] 王广德，过常龄，“Krige” 空间内插技术在地理学中的应 用 $[J]$. 地理学报, 1987 (04):366-375。

[22] 李天生, 周国法, 空间自相关与分布型指数研究 [J]. 生态 学报, 1994(03)：327-331。

[23] Rossi, R. E., Mulla D. J. and Journel A. G., Geostatistical tools for modeling and interpreting ecological spatial dependence [J]. Ecological. Monographs, 1992. $62(2)$ : p. 277-314.

[24] 王红梅, 王仲良，王斿等,华北农牧交错带农田-草地景观 镶嵌体土壤水分空间异质 [J]. 生态学报, 2013 (19): 6287-6294。

[25] Lichstein J W, Smons T R. and Shriner S A. Spatial autocorrelation and autoregressive models in ecology [J]. Ecological Monographs, 2002(72): p. 445-463.

[26] 赵安、孙九林、胡飞. 微地理环境钉螺空间分布的各向异性 克里格研究 $[J]$. 武汉大学学报 (理学版), 2007, 53 (S1) : 197-200。

[27] Fortin M J. Effects of sampling unit resolution on the estimation of spatial autocorrelation[J]. Ecoscience, 1999, 6(4): 636-641.

[28] Clark I. Statistics or geostatistics? Sampling error or nugget effect?[J]. The Journal of The Southern African Institute of Mining and Metallurgy, 2010, 10: 307-312.

[29] 尤海舟, 刘兴良, 缪宁等. 川滇高山栎种群不同海拔空间格 局的尺度效应及个体间空间关联 $[\mathrm{J}]$. 生态学报, 2010 , 30 (15)：4004-4011。

[30] Hill B G, Mcnew R W, Young J H and Ruth W E. The effects of sampling-unit size in some southwestern oklahoma cotton insects[J]. Environmental Entomology, 1975, 4(3) : 491-494.

[31] Cox G. W. (蒋有绪译). 普通生态学实验手册 [M]. 北京:科学 出版社, 1979。

[32] Kershaw K A. Quantitative and Dynamic Ecology[M]. London, Edward Arnold Publishers, 1964.

[33] Tobin P C. Estimation of the spatial autocorrelation function: consequences of sampling dynamic populations in space and time $[J]$. Ecography, 2004(27) : 767-775.

[34] Kershaw K A. Quantitative and Dynamic Ecology[M]. Edward Arnold Publishers, 1964. London.

[35] Bellehumeur C and Legendre P. Aggregation of sampling units: an analytical solution to predict variance[J]. Geographical analysis, 1997, $29(3)$ : 258-266.

[36] Rossi J P, Nuutinen A. The effect of sampling unit size on the perception of the spatial pattern of earthworm (Lumbricus terrestris L.) middens[J]. Applied Soil Ecology, 2004, 27: $189-196$. 
[37] 薛冬冬, 余光辉, 温小荣等, 基于地统计分析的南京钟山风 景区景观格局尺度效应分析 [J]. 西南林业大学学报, 2012(01)：30-35+111。
[38] 岳文泽, 徐建华, 谈文琦等, 城市景观多样性的空间尺度 分析一以上海市外环线以内区域为例 $[\mathrm{J}]$. 生态学报, 2005(01)：122-128。 